\title{
Luaran Klinis Anak dengan Epilepsi yang Mengalami Relaps Setelah Penghentian Obat Antiepilepsi
}

Agung Triono,* Elisabeth Siti Herini, ${ }^{*}$ Irawan Mangunatmadja**

*Departemen Ilmu Kesehatan Anak Fakultas Kedokteran Universitas Gadjah Mada, Yogyakarta

${ }^{* *}$ Departemen Ilmu Kesehatan Anak Fakultas Kedokteran Universitas Indonesia, Jakarta

Latar belakang. Penghentian obat antiepilepsi (OAE) yang terburu-buru meningkatkan risiko relaps. Risiko resistensi obat pada anak dengan epilepsi yang mengalami relaps sangat tinggi. Hingga saat ini belum ada kesepakatan mengenai pengobatan kejang pasca relaps. Tujuan. Penelitian ini bertujuan untuk mengetahui insiden relaps, karakteristik, prediktor, luaran, dan perjalanan elektroensefalografi (EEG) anak dengan epilepsi setelah mengalami relaps.

Metode. Penelitian dilakukan pada Juni-Desember 2016. Desain studi adalah potong lintang, multisite dari rekam medis tahun 2012-2016. Subjek adalah anak dengan epilepsi yang mengalami relaps.

Hasil. Epilepsi relaps terjadi paling banyak dalam tahun pertama setelah dosis OAE diturunkan, 41,3\% relaps terjadi dalam 6 bulan, dan 31,7\% antara 6-12 bulan. Riwayat waktu kejang terkontrol lama ( $\geq 1$ tahun) pada kejang sebelumnya merupakan faktor yang memengaruhi (RP 1,846 95\% IK 1,056 - 3,228) kejang yang tidak terkontrol dalam waktu 6 bulan pasca relaps. Sementara variabel lain tidak signifikan berpengaruh terhadap terkontrolnya kejang dalam 6 bulan pasca relaps.

Kesimpulan. Anak dengan epilepsi relaps yang memiliki riwayat waktu terkontrol kejang lama ( $\geq 1$ tahun) akan lebih sulit mencapai remisi kedua pasca relaps. Sari Pediatri 2019;20(6):335-41

Kata kunci : pasca relaps, epilepsi anak, luaran, obat antiepilepsi

\section{Clinical Outcome of Children with Epilepsy Who Had Relapse after Antiepileptic Drugs Withdrawal}

Agung Triono, ${ }^{*}$ Elisabeth Siti Herini, ${ }^{*}$ Irawan Mangunatmadja**

Background. Inappropriate antiepileptic drugs (AED) withdrawal increases the risk of relapse. The risk of drug resistance in children with epilepsy who had relapse is very high. There is no consensus about therapy for post-relapse seizure.

Objective. This study aims to know the incidence of relapse, the characteristics, predictors, outcomes, and electroencephalography (EEG) evolutions in children with epilepsy who had relapsed.

Methods. This study was held from June-December 2016. This was cross sectional study, multisite medical record evaluation from 2012-2016. The subjects were children with epilepsy who had relapse.

Result. Relapse epilepsy occurred mostly within the first year after AED withdrawal, 41,3\% relapse occurred in 6 months, and $31.7 \%$ between 6-12 months. History of slow time to seizure control ( $\geq 1$ year) was an influencing factor (RP 1,846 95\% CI 1,056-3,228) for uncontrolled seizure within 6 months after relapse. While the other variables did not significantly affect seizure control within 6 months after relapse.

Conclusion. Children with relapse epilepsy who had history of slow seizure-controlled time ( $\geq 1$ year) will be more difficult to achieve secondary remission after relapse.Sari Pediatri 2019;20(6):335-41

Keywords: post relapse, child epilepsy, outcome, antiepileptic drugs

Alamat korespondensi: Agung Triono. Departemen Ilmu Kesehatan Anak Fakultas Kedokteran Universitas Gadjah Mada, Yogyakarta. Email: agungtrionodr@yahoo.com 
7 ergesa-gesa dalam menurunkan OAE meningkatkan risiko relaps dan membuar epilepsi sulit mencapai remisi. ${ }^{1,2}$ Seorang anak dengan epilepsi yang tidak mengalami kejang setidaknya membutuhkan waktu dua tahun dengan terapi dan dikatakan mencapai kondisi remisi Berdasarkan hal tersebut, dosis OAE yang diturunkan secara bertahap selama periode 6-12 bulan dapa dipertimbangkan sebelum akhirnya dihentikan . $^{3,45}$ Pasien yang telah berhenti dari pengobatan dan tidak mengalami kejang selama minimal 2 tahun dikatakn telah mencopai kondisi remisi komplit.

Relaps merupakan suatu kondisi pasien mengalami iang kembali saat OAE diturunkan atau setelh dihentikan. ${ }^{5}$ Risiko relaps pada ank dengan epile dihentikan.' Risiko relaps pada anak dengan epileps sekit $16 \%-56 \%$ ren selap akan mengalani resist sidi obt. ${ }^{2}$ Mencrut penelitian seben ya tingke insiden relaps sebesar 28,6\% separth relaps tejadi pala san penuran dosis OAE dan sejo menunjukan, relapstejadi pada $36 \%$ subjek penelitian. Kejang relaps pada umumnya bersifat lebih ringan da cepat berhenti dibanding kejang sebelumnya.

Kejang fokal merupakan prediktor untuk terjadinya relaps yang dilaporkan pada beberapa penelitian. Berdasarkan penelitian lain, epilepsi simptomatik dan adanya keterlambatan perkembangan merupaka faktor prediktor terjadinya relaps. ${ }^{6,8,1}$ Risiko relaps jug lebih tinggi dilaporkan pada pasien yang menerima politerapi. ${ }^{5,8}$ Bangkitan kejang yang frekuen dan lam sebelum mengalami remisi merupakan faktor predikto relaps yang dilaporkan pada beberapa studi. Kejang berkepanjangan dan berulang dilaporkan menyebabkan kerusakan parenkim otak dan menurunkan ambang batas kejang. ${ }^{5,8,12}$ Elektroensefalografi abnormal merupakan prediktor pada epilepsi relaps. ${ }^{6,78}$ Hingga saat ini, belum ada penelitian yang menjelaskan pengaruh variabel tersebut terhadap kejang terkontrol pada pasien epilepsi pasca relaps. Sebanyak 38,9\% pasien epilepsi anak mengalami relaps kedua dan $16,7 \%$ pasien mengalami relaps ketiga.

Penelitian ini bertujuan untuk mengetahui insidensi relaps, karakteristik, prediktor, luaran dan perjalanan elektroensefalografi (EEG) anak dengan epilepsi setelah mengalami relaps.

\section{Metode}

Desain penelitian adalah potong lintang dari beberapa tempat (RSUP DR Sardjito Yogyakarta, RSU Condong Catur Yogyakarta, Klinik Anak Prof Sunartini dan Klinik Anak Prof Herini) di Yogyakarta. Sampe diambil secara consecutive dari rekam medis tahu 2012-2016. Studi rekam medis dilanjutkan dengan wawancara dan pemeriksaan EEG. Data yan digunakan adalah kelompok kasus (relaps) dari penelitian "Faktor Prediktor Relaps pada Epilepsi Anak setelah Penghentian Obat Antiepilepsi: Studi KasusKontrol" yang diikuti selama 6 bulan pasca relaps. Penelitian ini dilakukan pada Juni-Desember 2016.

Populasi dari penelitian ini adalah semua ana

Popul-18 dar pon Kriteria inklusi subjek adalah anos epilepsi relaps.

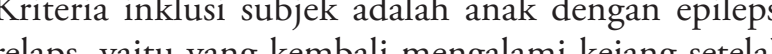
dosis setela obat dihentika minimal pasien sudah 2 tahun bebas kejang dengan bat. Semua subjek harus mendapat persetujuan dari orang tua/wali untuk berpartisipasi dalam penelitia ini. Kriteria eksklusi adalah data rekam medis yan tidak lengkap.

Penelitian ini telah disetujui oleh Medical and Health Research Ethics Committee (MHREC) Fakultas Kedokteran Universitas Gadjah Mada (Ref: KE K/780/EC/2016). Informed-consent untuk ikut serta dalam penelitian ini diperoleh dari semua orang tua

Semua rekam medis dari 2012-2016 dengan diagnosis epilepsi relaps dikelompokkan berdasarka waktu kejang terkontrol, dan dilakukan wawanca untuk memperoleh data pasca relaps serta menjalani pemeriksaan EEG.

Data pasca relaps dianalisis untuk melihat karakteristik dan evolusi EEG pada subjek epileps relaps. Definisi kejang terkontrol dalam 6 bulan pasca relaps adalah tercapainya bebas kejang selama minima tiga bulan berturut-turut dalam enam bulan pertam setelah diberikan OAE dengan jenis dan dosis yang tepat. Sementara kejang belum terkontrol dalam 6 bulan pasca relaps adalah masih adanya kejang dalam 3 bulan terakhir dalam 6 bulan pertama setelah diberikan OAE.

Evolusi EEG I adalah perbandingan antara EEG saat terdiagnosis epilepsi dan saat akan menurunka dosis OAE. Evolusi EEG II adalah perbandingan EEG antara saat akan menurunkan OAE dan ketik pasien mengalami relaps. Evolusi EEG memburuk jil frekuensi gelomang epilepsi meningkat atau ad jin evolusi EEG membaik jika gelombang epileptiform menghilang atau berkurang atau tidak ada gelombang perlambatan dibanding EEG sebelumnya.

Data dianalisis dengan program SPSS 22.0. Data dianalisis secara deskriptif, dilanjutkan dengan analisis bivariat untuk masing-masing variabel. Nilai $\mathbf{p}<0,05$ dianggap signifikan.

\section{Hasil}

Subjek pada penelitian ini adalah 63 kasus epilepsi relaps yang didapatkan dari penelitian "faktor prediktor relaps pada anak dengan epilepsi setelah penghentian obat antiepilepsi:studi kasus-kontrol" yang kemudian diikuti selama 6 bulan terapi pasca relaps.

Kejadian relaps sebagian besar (73\%) terjadi pada tahun pertama. Sebanyak $41,3 \%$ epilepsi relaps terjad

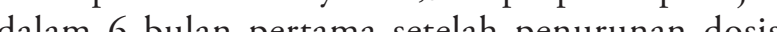
chen 6 bulan pertana setelah penturunan dosis/ per bulan. Proporsi relaps yang tejadi pada 612 bulan (1,7\%, dontan Pada 1-2 tahun pasca penurunan obat kejadian relaps

\begin{tabular}{lcccc}
$\begin{array}{l}\text { Tabel 1. Proporsi dan rerata waktu relaps } \\
\text { Waktu relaps pasca penurunan OAE }\end{array}$ & $\mathrm{n}$ & $\%$ & $\begin{array}{c}\text { Rerata } \\
\text { (bulan) }\end{array}$ & SE \\
\hline$<6$ bulan & 26 & 41,3 & 1,43 & 0,41 \\
$6-12$ bulan & 20 & 31,7 & 8,55 & 0,37 \\
$1-2$ tahun & 9 & 14,3 & 17,40 & 1,52 \\
$>2$ tahun & 8 & 12,7 & 41,10 & 4,67 \\
\hline Total & 63 & 100 & 11,00 & 1,73 \\
\hline
\end{tabular}

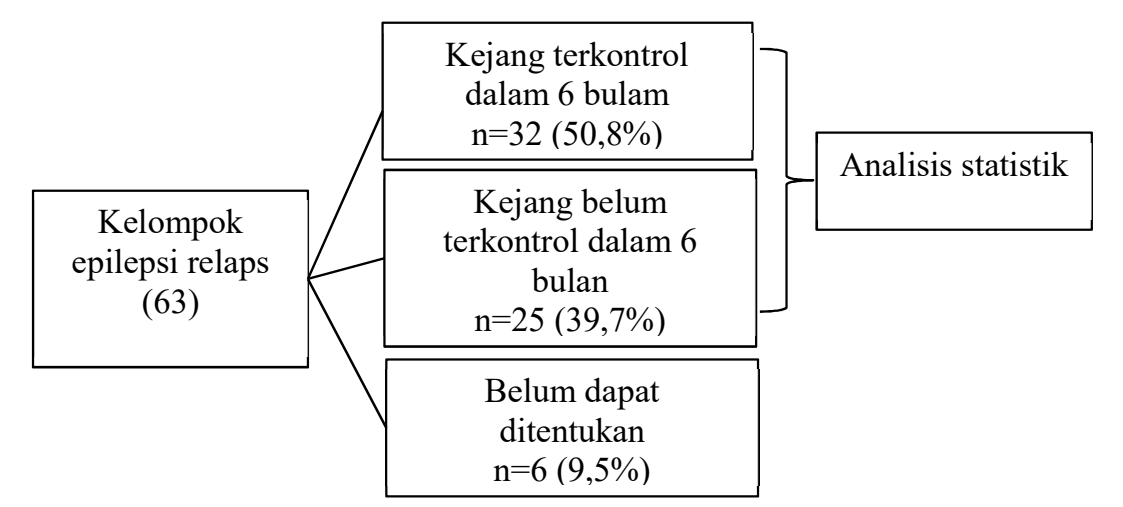

Gambar 1. Perjalanan outcome epilepsi relaps
$14,3 \%$, dengan rerata waktu kejadian 17,4 bulan, dan kejadian relaps setelah 2 tahun pasca penurunan dosis/ penghentian obat sebesar 12,7\%, dengan rerata waktu kejadian 41,1 bulan (Tabel 1). Rerata waktu relaps pada penelitian ini adalah 11 bulan pasca penurunan/

Setelah diikuti selama 6 bulan pasca relaps didapatkan $32(50,8 \%)$ subjek dengan kejang terkontrol dalam 6 bulan terapi, 25 (39,7\%) subjek dengan kejang belum terkontrol dalam 6 bulan terapi, dan $6(9,5 \%)$ subjek tidak dikutsertakan dalam analisis karena terapi belum 6 bulan. Lima puluh tujuh sampel yang terbagi dalam 2 kelompok (kejang terkontrol dalam 6 bulan pasca relaps dan kejang belum terkontrol lan pasca relaps) kemudian dianalisis (Gambar 1).

Data kemudian dilakukan analisis subgroup Rerata usia kelompok dengan kejang terkontrol dalam rerk

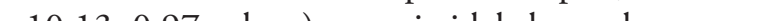
ve statistik $(\mathrm{p}=0,763)$. Rerata usia onset penyakt kelompok . 
$(4,40 \pm 0,93$ vs $4,36 \pm 0,90)$, tetapi perbedaan ini tidak bermakna secara statistik $(\mathrm{p}=0,980)$. Selisih waktu antara gejala muncul hingga ditegakkan diagnosis lebih tinggi pada kelompok kejang belum terkontrol dalam 6 bulan pasca relaps dibanding kelompok yang relapsnya terkontrol dalam 6 bulan $(2,15 \pm 0,62$ vs $1,87 \pm 0,65)$ tetapi perbedaan ini juga tidak bermakna secara statistil

$(\mathrm{p}=0,763)$ (Tabel 2).

Berdasarkan analisis bivariat, variabel yang signifikan berpengaruh terhadap kejang terkontro dalam 6 bulan pasca relaps adalah lamanya waktu untuk mengontrol kejang sebelumnya. Jika dijumpai riwayat waktu untuk mengontrol kejang lambat ( 21 tahun), akan meningkatkan risiko kejang tidak

Tabel 2. Karakteristik usia subjek epilepsi relaps $(\mathrm{n}=57)$

\begin{tabular}{lcccc}
\hline & Total & $\begin{array}{c}\text { Kejang belum terkontrol } \\
\text { dalam 6 bulan }\end{array}$ & $\begin{array}{c}\text { Kejang terkontrol } \\
\text { dalam 6 bulan }\end{array}$ & $\mathrm{p}$ \\
\hline & $(\mathrm{n}=57)$ & $(\mathrm{n}=25)$ & $(\mathrm{n}=32)$ & \\
& Rerata $\pm \mathrm{SE}$ & Rerata $\pm \mathrm{SE}$ & Rerata $\mathrm{SE}$ & \\
Usia saat relaps & $9,90 \pm 0,66$ & $10,13 \pm 0,91$ & $9,73 \pm 0,94$ & 0,763 \\
Usia onset epilepsi & $4,38 \pm 0,65$ & $4,36 \pm 0,90$ & $4,40 \pm 0,93$ & 0,980 \\
Selisih waktu antara gejala dan diagnosis & $2,00 \pm 0,45$ & $2,15 \pm 0,62$ & $1,87 \pm 0,65$ & 0,763 \\
\hline
\end{tabular}

Tabel 3. Karakteristik subjek epilepsi relaps ( $\mathrm{n}=57$ )

\begin{tabular}{|c|c|c|c|c|c|c|c|}
\hline \multirow[t]{2}{*}{ Karakteristik } & \multicolumn{2}{|c|}{$\begin{array}{l}\text { Kejang belum terkontrol } \\
\text { dalam } 6 \text { bulan } \\
(\mathrm{n}=25)\end{array}$} & \multicolumn{2}{|c|}{$\begin{array}{l}\text { Kejang terkontrol } \\
\text { dalam } 6 \text { bulan } \\
(\mathrm{n}=32)\end{array}$} & \multirow[t]{2}{*}{$\mathrm{p}$} & \multirow[t]{2}{*}{ PR } & \multirow[t]{2}{*}{ IK 95\% } \\
\hline & $\mathrm{n}$ & $\%$ & $\mathrm{n}$ & $\%$ & & & \\
\hline \multicolumn{8}{|l|}{ Jenis kelamin } \\
\hline Laki-laki & 13 & 22,8 & 12 & 21,1 & \multirow[t]{2}{*}{0,274} & \multirow{2}{*}{1,387} & \multirow{2}{*}{$0,773-2,488$} \\
\hline Perempuan & 12 & 21,1 & 20 & 35,1 & & & \\
\hline \multicolumn{8}{|l|}{ Etiologi } \\
\hline Simtomatik & 19 & 33,3 & 21 & 36,8 & \multirow[t]{2}{*}{0,396} & \multirow[t]{2}{*}{1,346} & \multirow[t]{2}{*}{$0,654-2,769$} \\
\hline Idiopatik & 6 & 10,5 & 11 & 19,3 & & & \\
\hline \multicolumn{8}{|c|}{ Riwayat waktu kejang terkontrol } \\
\hline Lambat ( $\geq 1$ tahun) & 12 & 21,1 & 7 & 12,3 & \multirow[t]{2}{*}{0,038} & \multirow[t]{2}{*}{1,846} & \multirow[t]{2}{*}{$1,056-3,228$} \\
\hline Cepat $(<1$ tahun $)$ & 13 & 22,8 & 25 & 43,9 & & & \\
\hline \multicolumn{8}{|l|}{ Tipe kejang } \\
\hline Parsial & 6 & 10,5 & 3 & 5,3 & \multirow[t]{2}{*}{0,133} & \multirow[t]{2}{*}{1,684} & \multirow[t]{2}{*}{$0,944-3,006$} \\
\hline General & 19 & 43,9 & 29 & 50,9 & & & \\
\hline \multicolumn{8}{|l|}{ Terapi } \\
\hline Politerapi & 3 & 5,3 & 3 & 5,3 & \multirow{2}{*}{0,749} & \multirow{2}{*}{1,159} & \multirow[t]{2}{*}{$0,491-2,739$} \\
\hline Monoterapi & 22 & 38,6 & 29 & 50,9 & & & \\
\hline \multicolumn{8}{|c|}{ Riwayat status epileptikus } \\
\hline Ada & 7 & 12,3 & 4 & 7,0 & \multirow[t]{2}{*}{0,141} & \multirow[t]{2}{*}{1,626} & \multirow[t]{2}{*}{$0,916-2,887$} \\
\hline Tidak ada & 18 & 31,6 & 28 & 49,1 & & & \\
\hline \multicolumn{8}{|l|}{ Riwayat kejang demam } \\
\hline Ada & 10 & 17,5 & 14 & 24,6 & \multirow[t]{2}{*}{0,776} & 0,917 & $0,502-1,676$ \\
\hline Tidak ada & 15 & 26,3 & 18 & 31,6 & & & \\
\hline Riwayat epilepsi di kel & & & & & & & \\
\hline Ada & 5 & 8,8 & 5 & 8,8 & 0,667 & 1,175 & $0,582-2,374$ \\
\hline Tidak ada & 20 & 35,1 & 27 & 47,4 & & & \\
\hline
\end{tabular}

* $=$ signifikan $(\mathrm{p}<0,05)$

Tabel 4. Karakteristik evolusi EEG pada pasien relaps

\begin{tabular}{|c|c|c|c|c|c|c|c|}
\hline \multirow[t]{2}{*}{ Evolusi EEG } & \multicolumn{2}{|c|}{$\begin{array}{l}\text { Kejang belum terkontrol } \\
\text { dalam } 6 \text { bulan }\end{array}$} & \multicolumn{2}{|c|}{$\begin{array}{l}\text { Kejang terkontrol dalam } \\
6 \text { bulan }\end{array}$} & \multirow[t]{2}{*}{$\mathrm{p}$} & \multirow[t]{2}{*}{ PR } & \multirow[t]{2}{*}{ IK 95\% } \\
\hline & $\mathrm{n}$ & $\%$ total & $\mathrm{n}$ & $\%$ total & & & \\
\hline \multicolumn{8}{|c|}{ Evolusi EEG I ( $\mathrm{n}=57)$} \\
\hline Memburuk & 19 & 33,3 & 17 & 29,8 & 0,076 & 1,847 & $0,878-3,885$ \\
\hline Membaik & 6 & 10,5 & 15 & 26,3 & & & \\
\hline \multicolumn{8}{|c|}{ Evolusi EEG II ( $\mathrm{n}=41)$} \\
\hline Memburuk & 15 & 36,6 & 16 & 39,0 & 0,113 & 2,419 & $0,665-8,805$ \\
\hline Membaik & 2 & 4,9 & 8 & 19,5 & & & \\
\hline
\end{tabular}
terkontrol dalam 6 bulan terapi pasca relaps sebesar
$1,846$ kali (IK $95 \% 1,056-3,228, \mathrm{p}<0,05)$ (Tabel 3). Evolusi EEG I (EEG saat penegakkan diagnosi dibandingkan saat penurunan dosis) tidak berpengaruh terhadap kontrol kejang pasca relaps $(\mathrm{p}=0,076)$. Saat (

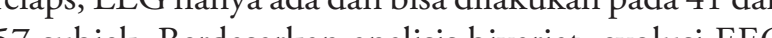
II (pe) . Be II (perandingan EeG antara penumnan dosis dan sat te jadiny relps) juga tidak be1pengaruh terhap kontrol kejang paska relaps $(\mathrm{p}=0,113)$ (Tabel 4).

\section{Pembahasan}

Angka kejadian relaps diambil dari data penelitian Faktor Prediktor Relaps pada Epilepsi Anak setela Penghentian Obat Antiepilepsi: Studi Kasus-Kontrol yaitu sebesar $13,6 \%$. Tingkat insiden relaps yang sebenarnya mungkin lebih dari 13,6\% karena ad beberapa subjek yang dieksklusi akibat data rekan medis yang tidak lengkap. Beberapa penelitia melaporkan berbagai tingkat insiden epilepsi relaps sebesar 6\%-39\%.

Berdasarkan analisis univariat, waktu kejadian relaps sebagian besar terjadi pada tahun pertama, terutama pada 6 bulan pertama, yaitu pada saat proses penurunan obat (tapering off). Hasil penelitian ini hampir sama dengan penelitian sebelumnyayang melaporkan bahwa $50 \%$ epilepsi relaps terjadi saat penurunan dosis obat dan sisanya setelah OAE dihentikan. ${ }^{6}$ Meta-analisis cumulative probability relaps pada tahun pertama sejak mulai penurunan obat sebesar $25 \%$ dan pada tahun kedua sebesar $29 \%$.

Menurut penelitian sebelumnya, onset umur epilepsi antara 4-12 then memengaruhi kejadion plaps. 7,8,14 Umur muda mempunyai ketahana lebih baik terhadap kejadian kejang. Hal tersebut karena anak umur muda mempunyai plastisitas otak yang masih baik. ${ }^{15}$ Pada penelitian ini didapatkan usia onset epilepsi pada kelompok kejang yang terkontrol dalam 6 bulan lebih tinggi dibandingkan kelompok relaps tidak terkontrol dalam 6 bulan, tetapi perbedaan ini tidak bermakna secara statistik. Sementara usia saat terjadinya relaps dan selisih waktu antara onset pertama gejala dan penegakkan diagnosis lebih muda pada kelompok kejang yang erkontrol dalam 6 bulan pasca relaps, tetapi kedua hasil ini tidak bermakna secara statistik. Berdasarkan penelitian ini dapat disimpulkan bahwa onset usia epilepsi, dan selisih antara gejala dan penegakan diagnosis tidak berpengaruh terhadap waktu kejang terkontrol pasca relaps.

Jenis kelamin subjek perempuan lebih banyak dibanding laki-laki. Berdasarkan analisis bivariat, kelompok laki-laki lebih berisiko untuk kejang tidak terkontrol dalam 6 bulan, tetapi tidak bermakna secara demikian dapat disimpulkan bahwa dak berpengaruh terhadap kontrol kejang pasca relaps.

Etiologi epilepsi simptomatik pada seluruh subjek lebih banyak dibanding epilepsi idiopatik. Definisi operasional epilepsi simtomatik tidak hanya didasarkan pada hasil CT scan atau MRI kepala, tetapi juga ketika dijumpai kelainan neurologis, epilepsi post meningitis, epilepsi etiologi genetik, dan epilepsi yang dipastikan ada kelainan neuroanatomis dan neuropatologis di dalam otak meskipun tidak ada hasil CT scan., ${ }^{3,16,17}$ Berdasarkan analisis bivariat, etiologi epilepsi tidak berpengaruh terhadap kejang terkontrol dalam 6 bulan pasca relaps

Waktu kejang terkontrol yang lambat merupakan prediktor teriadinya relaps pada 11 penelitian 8,18 $^{8} \mathrm{Pada}$ penelitian ini juga didapatkan hasil bahwa seorang dengan riway waku kejang teckotol yang ba 
akan memengaruhi waktu kejang terkontrol pasca relaps. Kejang yang lama, berkepanjangan, da berulang dapat menyebabkan pembentukan fokus epileptogenik melalui kindling model. Selain itu dapat juga disebabkan akibat adanya farmakoresisten obat. ${ }^{12,19,20}$ Berdasarkan penelitian Callaghan dkk, ${ }^{11}$ setengah dari pasien relaps mencapai remisi kedua setelah 12 bulan terapi. Beberapa pasien epilepsi relaps dapat memiliki lebih dari satu kejadian relaps. Sebanyak 7/18 pasien mengalami relaps kedua dan $3 / 18$ pasien mengalami relaps ketiga.

Tipe kejang pada pada penelitian ini lebih banyak

kejang umum dibanding kejang fokal. Beberapa kejang um sebelumny melaporkan. Beberap. peneltian sebech ris kejang 19,21-23 sed tidak 7 Berdan tidak. Be sed pengaruh tipe kejang pada passen pasca relaps terhadap

Pada penelition ini, sebaginn pesar

Pada penelitian ini, sebaglan besar subjek menjalan pengoban monopi Regin yang digunakan adalah asan valproat. Pada penelitian sebelumnya kondisi pasien berpengaruh kepad penggunaan obat anti epilepsi apakah menggunakan regimen monoterapi atau politerapi. Namun, pad penelitian ini tidak didapatkan pengaruh banyakny regimen obat terhadap terkontrolnya kejang dalam 6 ulan pasca relaps.

Riwayat status epileptikus akan memengaruh lama kejang terkontrol sehingga berhubungan dengan lamanya kontrol kejang pasca relaps. Namun, pad penelitian ini didapatkan bahwa riwayat adanya statu epileptikus tidak bermakna berpengaruh terhada kejang terkontrol pasca relaps. Hal ini mungkin disebabkan karena proporsi pasien dengan status epileptikus sedikit. Begitu pula dengan riwayat kejang demam dan riwayat epilepsi pada keluarga yang tidak berpengaruh bermakna terhadap terkontrolnya kejang dalam 6 bulan pasca relaps.

Belum ada kesepakatan terkait protokol pemberian OAE pasca relaps (berapa lama diberikan, kapan dilakukan evaluasi, hingga kapan dosis diturunkan dan seberapa cepat penurunannya). Diperlukan penelitian untuk memberikan masukan pada protokol terapi OAE pasca relaps. Lama terapi pasca relaps kurang dari 1 tahun memungkinan terjadinya relaps kedua. Meskipun demikian hal ini masih perlu penelition prospektif dengan subjek pasca repos yang lebih besar dengan desain prospektif.

\section{Kesimpulan}

Waktu munculnya relaps sebagian besar terjadi pada tahun pertama setelah OAE diturunkan ata dihentikan. Kejadian relaps dalam tahun pertam pada penilitian ini adalah $73 \%$, pada 6 bulan pertam pada pen. 41 . Dari terkontrol kembali sebelum 6 bu denayat pasien cena $(\geq 1$ tahun) dalam 6 bulan pasca relaps.

\section{Saran}

Karena riwayat waktu terkontrolnya kejang yang ama pada anak dengan epilepsi merupakan predikto tidak terkontrolnya kejang pasca relaps, maka apabila dijumpai faktor tersebut pengobatan harus lebih agresi dan tidak terburu-buru untuk menurunkan dosis OAE. erlu dilakukan penelitian lebih lanjut untuk membuat protokol OAE pasca relaps, diantaranya berapa lama OAE harus diberikan, kapan dilakukan evaluasi, kapa dan seberapa cepat dosis OAE diturunkan.

\section{Daftar pustaka}

1. Browne TR \& Holmes GL. Handbook of epilepsy. Edisi keempat. Philadelphia: Lippincott Williams \& Wilkins; 2008. Specchio LM \& Beghi E. Should antiepileptic drugs be wi in seizure-free patients? CNS Drugs 2004;18:201-12.

3. Berg AT \& Shinnar S. Relapse following discontinuation of antiepileptic drugs: a meta-analysis. Neurology 1994;44:601-8.

4. Fisher RS, Acevedo C, Arzimanoglou A, dkk. ILAE Official Report: A practical clinical definition of epilepsy. Epilepsi 2014:55:475-82.

5. Pavlović M, Jović N, \& Pekmezović T. Antiepileptic drugs withdrawal in patients with idiopathic generalized epileps. Seizure 2011;20:520-5.

6. Verrotti A, D’Egidio C, Agostinelli S, dkk. Antiepileptic drug withdrawl in childhood epiles: Wh ante he risk

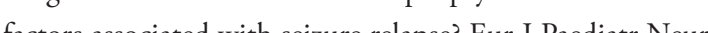
(2012,16.599-604.

Shinnar S, Berg AT, Moshé SL, dkk. Discontinuing antiepileptic drugs in children with epilepsy: A prospective study: Discontinuing Antiepileptic Medications. Ann Newrol
1994;35:534-45.

8. Beghi E, Giussani G, Grosso S, dkk. Withdrawal of antiepileptic drugs: guidelines of the Italian League Again Epilepsy. Epilepsia 2013;54 Suppl 7:2-12

9. Braathen $\mathrm{G} \&$ Melander $\mathrm{H}$. Early discontinuation of treatment in children with uncomplicated epilepsy: a prospective study with a model for prediction of outcome. Epilepsia 1997;38:561-9.

10. Hawash KY \& Rosman NP. Do partial seizures predict an increased risk of seizure recurrence after antiepilepsy druss are withdrawn? J Child Neurol 2003;18:331-7

11. Callaghan B, Schlesinger M, Rodemer W, dkk. Remission and relapse in a drug-resistant epilepsy population followed prospectively: Drug-Resistant Epilepsy Population. Epilepsia 2011;52:619-26.

12. Holmes GL \& Ben-AriY. The neurobiology and consequences of epilepsy in the developing - Olmez A, Arshe U, Turati $\mathrm{G}$ Aysun S. Risk of recurence

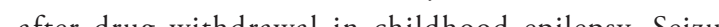
2009;18:251-6.

14. Mastropaolo C, Tondi M, Carboni F, Manca S, Zorodd F. Prognosis after therapy discontinuation in children with epilepsy. Eur Neurol 1992;32:141-5.

15. Mangungatmaja I. Prediksi luaran klinis pasien epileps fokal berusia kurang dari 3 tahun: peran evolusi klinis da elektroensefalografi serta Magnetic Resonance Imaging tesis. Universitas Indonesia, Program Studi Doktor Ilmu Kedokteran, 2012.

16. Peters AC, Brouwer OF, Geerts AT, Arts WF, Stroink H, van Donselaar CA. Randomized prospective study of early discontinuation of antiepileptic drugs in children with epilepsy. Neurology 1998;50:724-30.

17. Ramos-Lizana J, Aguirre-Rodríguez J, Aguilera-López P, \& Cassinello-García E. Recurrence risk after withdrawal of antiepileptic drugs in children with epilepsy: A prospective study. Eur J Pediatr Neurol 2010;14:116-24.

18. Thurston JH, Thurston DL, Hixon BB, Keller AJ. Prognosis in childhood epilepsy: additional follow-up of 148 children 15 to 23 years after withdrawal of anticonvulsant therapy. N Eng J Med 1982;306:831-6.

19. Morrell F. Secondary epileptogenesis in man. Arch Neurol 1985;42:318-35.

20 Sadzot B. Epilepsy: a progressive disease? BMJ 1997;314:391-2.

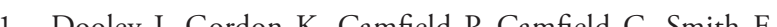
Discontinution of anticonvalent heapy in childen Disco fiec of

22. Matricardi M, Brinciotti M, Benedetti P. Outcome after discontinuation of antiepileptic drug therapy in children with epilepsy. Epilepsia 1989;30:582-9.

23. Sillanpaa M. Remission of seizures and predictors of intractability in long-term follow-up. Epilepsia 1993;34:930-6. 